\title{
Hand Gesture Recognition for Differently Abled People with Message Integration.
}

\author{
G. Prashanth Kumar., G. Vamsi Krishna Reddy
}

\begin{abstract}
The objective of this paper is to utilize a webcam to lively track the region of interest (ROI), in particular, the hand

locale, in the picture extend and recognize hand motion, we use skin colour discovery and also morphology to delete the unnecessary background information from the picture, and afterward use foundation subtraction to recognize the ROI. Next, to stay away from foundation effects on items or commotion influencing the ROI, we utilize the kernelized connection channels (KCF) calculation to follow the identified ROI. The picture size of the $\mathrm{ROI}$ is at that point resized to $28 \times 28$ and afterward sent into the profound convolutional neural system (CNN), so as to distinguish

various hand signals. Two profound CNN designs are created right now are altered from DenseNet . At that point, the above procedure of following and acknowledgment is rehashed to accomplish a moment impact, and the framework's execution proceeds until the hand is removed from the camera.
\end{abstract}

Keywords: Hand tracking; KCF; DCNN; hand gesture recognition

\section{INTRODUCTION}

People speak with one another by passing on their thoughts, contemplations, and encounters to the individuals around them. There are various approaches to accomplish this and the best one among all is the endowment of "discourse". The main methods for correspondence for hard of hearing and unable to speak individuals is the "gesture-based communication". It will be unfair on the off chance that we disregard the individuals who are denied of this priceless blessing. Hard of hearing moronic individuals need to speak with ordinary individuals for their day by day schedule. There are a few troubles when they run over in specific zones like banking, emergency clinic. India establishes 2.4 million of hard of hearing and unable to speak populace.

The gesture-based communication is significant for hearing hindered individuals. Finding an informed interpreter for the communication via gestures inevitably and wherever is troublesome errand. The human-PC cooperation framework is useful for imbecilic individuals to defeat the trouble, other than it and can be introduced anyplace. This undertaking proposes the technique or calculation for an application which would help in perceiving the various signs and convert those sign signals into some message. The communications through signing for various numbers in words are trained and tested.

Revised Manuscript Received on April 18, 2020.

* Correspondence Author

G. Prashanth Kumar*, Dept. of Computer Science and Engineering, SRM Institute of Science and Technology, Chennai, India gurijalaprashanth4@gmail.com

G. Vamsi Krishna Reddy, Dept. of Computer Science and Engineering, SRM Institute of Science and Technology, Chennai, Indiavamsikrishnareddygottu9@gmail.com

(c) The Authors. Published by Blue Eyes Intelligence Engineering and Sciences Publication (BEIESP). This is an open access article under the CC BY-NC-ND license (http://creativecommons.org/licenses/by-nc-nd/4.0/)
The customary technique is to play out the acknowledgment by utilizing the convex hull of the hand after performing skin division. Acknowledgment is controlled by the total polygon edges produced by a hand motion, and just the numbers from 1 to 5 can be perceived.

This technique cannot be used to recognize complex gestures.

In this project we use a technique called convolutional neural network(CNN) is increasingly famous in the field of acknowledgment, and has preferred outcomes over other strategies, basically in light of the fact that it can get the necessary component esteems from the information picture, and can become familiar with the contrast between various examples well by utilizing countless examples in its preparation. Be that as it may, previously, its improvement has been constrained because of the speed of equipment processing. In later a long time, because of the progression of semiconductor producing, the figuring rate of illustrations preparing units is getting quicker, and the bottleneck of equipment preparing speed has been tended to, permitting the CNN system to grow quickly to turn into deep CNN.

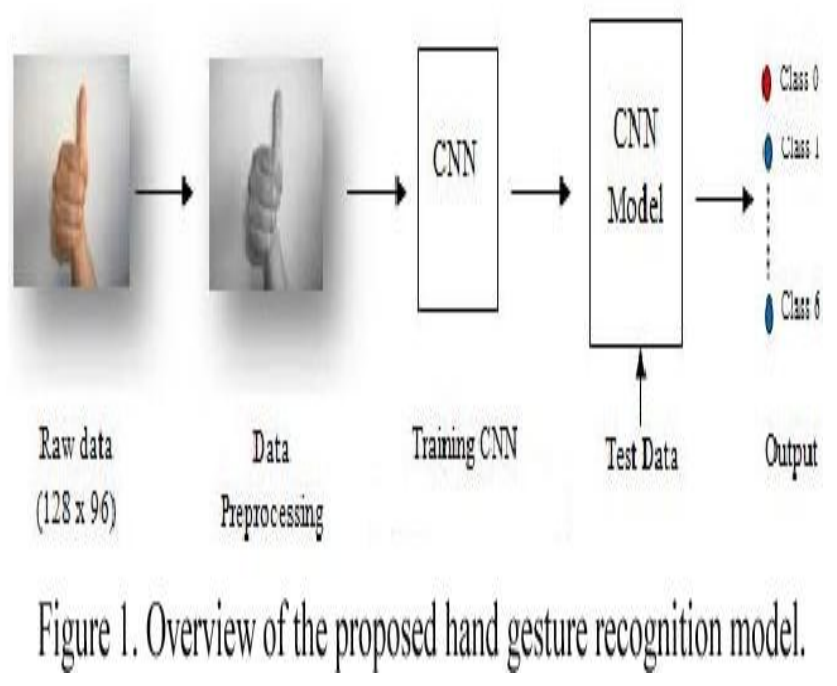

Published By:

Blue Eyes Intelligence Engineering \& Sciences Publication 
Hand Gesture Recognition for Differently Abled People with Message Integration.

\section{LITERATURE SURVEY}

\begin{tabular}{|c|c|c|c|c|}
\hline $\begin{array}{l}\text { RE } \\
\text { F. } \\
\text { NO. }\end{array}$ & TITLE & $\begin{array}{l}\text { APPROAC } \\
\text { H USED }\end{array}$ & OVERVIEW & INFERENCE \\
\hline \multirow[t]{7}{*}[1]{} & \multirow{7}{*}{$\begin{array}{l}\text { Hand Gesture } \\
\text { Recognition } \\
\text { Using Deep } \\
\text { Learning. }\end{array}$} & \multirow{7}{*}{$\begin{array}{l}\text { Deep learning, } \\
\text { neural } \\
\text { network, and } \\
\text { htransfer } \\
\text { learning }\end{array}$} & $\begin{array}{l}\text { The aim is to recognize six static and eig } \\
\text { ht }\end{array}$ & $\begin{array}{l}\text { In this paper, a hand gesture recogniti } \\
\text { on }\end{array}$ \\
\hline & & & $\begin{array}{l}\text { dynamic gestures while preserving Syste } \\
\mathrm{m} \\
\text { accuracy and speed. The recognized gest } \\
\text { ures }\end{array}$ & $\begin{array}{l}\text { approach based on vision is } \\
\text { implemented }\end{array}$ \\
\hline & & & $\begin{array}{l}\text { are for giving command to the } \\
\text { computer. }\end{array}$ & $\begin{array}{l}\text { using transfer learning. The approach } \\
\text { was }\end{array}$ \\
\hline & & & & $\begin{array}{l}\text { made reliable by } \\
\text { avoiding segmentation of }\end{array}$ \\
\hline & & & & $\begin{array}{l}\text { the skin color, blob identification, cro } \\
\text { pping }\end{array}$ \\
\hline & & & & $\begin{array}{l}\text { of the skin region and extraction of ce } \\
\text { ntroids }\end{array}$ \\
\hline & & & & for unidirectional dynamic gestures. \\
\hline \multirow[t]{3}{*}[2]{} & \multirow{3}{*}{$\begin{array}{l}\text { Hand Gesture } \\
\text { Recognition } \\
\text { based on } \\
\text { ShapeParamet } \\
\text { ers }\end{array}$} & \multirow{3}{*}{$\begin{array}{l}\text { Image } \\
\text { processing, } \\
\text { Human } \\
\text { computer } \\
\text { interaction } \\
\text { and K-means } \\
\text { clustering. }\end{array}$} & $\begin{array}{l}\text { The solution that this provides depends e } \\
\text { ntirely }\end{array}$ & Persons with visual impairments can \\
\hline & & & $\begin{array}{l}\text { on the form parameters of the hand gestu } \\
\text { re. }\end{array}$ & $\begin{array}{l}\text { use hand gestures to write text on ele } \\
\text { ctronic }\end{array}$ \\
\hline & & & & $\begin{array}{l}\text { documents such as } \\
\text { MS Office, notepad, etc. }\end{array}$ \\
\hline \multirow[t]{6}{*}[3]{} & A Static & \multirow{6}{*}{$\begin{array}{l}\text { Cascade } \\
\text { Classifier, } \\
\text { Convex Hull, } \\
\text { Haar like } \\
\text { features. }\end{array}$} & $\begin{array}{l}\text { For a blind person this can be helpful an } \\
\text { d }\end{array}$ & This system makes use of facial \\
\hline & $\begin{array}{l}\text { Hand Gesture } \\
\text { and Face } \\
\text { Recognition } \\
\text { System for } \\
\text { Blind People }\end{array}$ & & $\begin{array}{l}\text { can act as a virtual assistant to it. For fac } \\
\text { e } \\
\text { detection and identification in real time, } \\
\text { hair }\end{array}$ & recognition and hand gesture to help \\
\hline & & & $\begin{array}{l}\text { cascade classifiers and LBPH recognizer } \\
\mathrm{s}\end{array}$ & $\begin{array}{l}\text { and work with the environment to ma } \\
\text { ke }\end{array}$ \\
\hline & & & $\begin{array}{l}\text { were used, whereas Convex hull and Co } \\
\text { nvex }\end{array}$ & it a better place for the blind to live. \\
\hline & & & $\begin{array}{l}\text { defect algorithms were used to detect Ha } \\
\text { nd }\end{array}$ & \\
\hline & & & gestures in real time. & \\
\hline \multirow[t]{5}{*}[4]{} & \multirow{5}{*}{$\begin{array}{l}\text { Hand Gesture } \\
\text { Recognition } \\
\text { and Device } \\
\text { Control. }\end{array}$} & \multirow{5}{*}{$\begin{array}{l}\text { Hand Gesture } \\
\text { and } \\
\text { Microcontroll } \\
\text { er. }\end{array}$} & The system uses 2D visual information, & $\begin{array}{l}\text { The system uses } 2 \mathrm{D} \text { visual informatio } \\
\mathrm{n} \text {, }\end{array}$ \\
\hline & & & $\begin{array}{l}\text { which is obtained from a normal webca } \\
\mathrm{m} \text {, }\end{array}$ & $\begin{array}{l}\text { which is accessed from a standard we } \\
\text { bcam, }\end{array}$ \\
\hline & & & and controls the electrical drives of the & $\begin{array}{l}\text { which manages the electrical drives of } \\
\text { the }\end{array}$ \\
\hline & & & device by tracking and recognizing hand & $\begin{array}{l}\text { computer by detecting and understand } \\
\text { ing }\end{array}$ \\
\hline & & & gestures. & hand gestures. \\
\hline
\end{tabular}

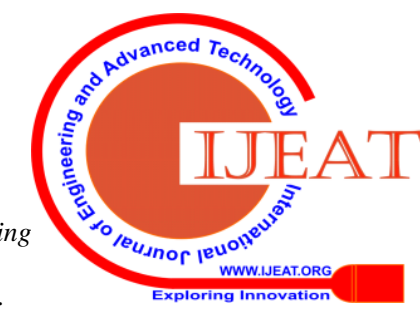




\section{PROPOSED WORK}

Fig. 1 is a schematic outline of the proposed in general hand signal acknowledgment idea, which adequately joins three key segments, in particular, Data preprocessing, Training the given images and Testing the given data. For the data preprocessing, we first perform skin division on input picture to expel the extra foundation data, and afterward process the clamor to decrease the little damage in certain pictures. The core concept is to extract the ROI features of the target position of the first frame and train a model. Then, after the next frame comes in, the trained model will do the calculation to get a new predicted position. As for the hand recognition aspect, we use the deep CNN network to extract and recognize the hand features.

BLOCK DIAGRAM

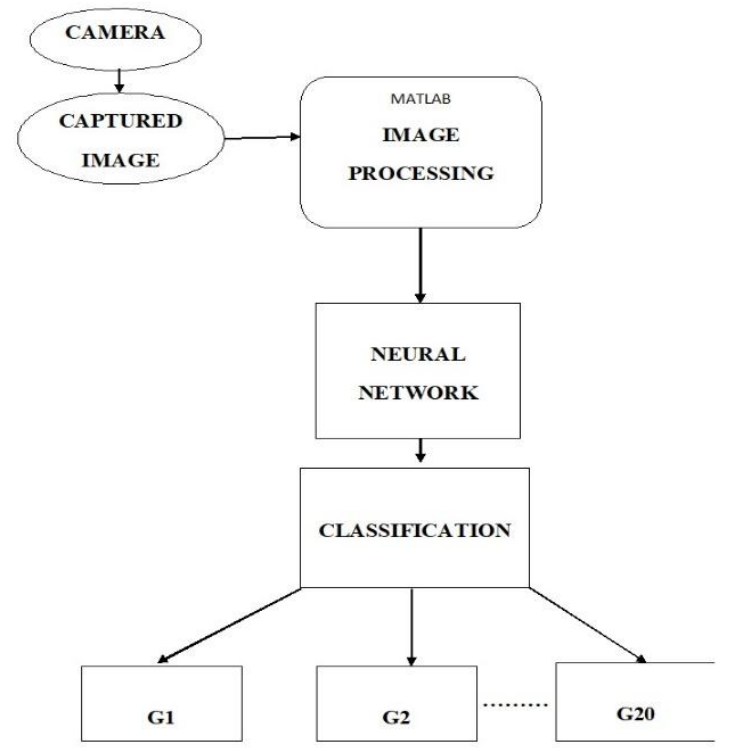

Figure2 Block diagram of proposed system

\section{Image Processing}

MATLAB stores most images as two-dimensional arrays (i.e. matrices), in which each matrix element corresponds to one single pixel in the depicted image. (Pixels are derived from the picture factor and typically repr esent a single point on a computer display.)

For example, an image in MATLAB would be stored as a 200-by-300 matrix composed of 200 rows and 300 columns of different colored dots. Many images, such as true color images, involve a three-dimensional array where the first plane in the third dimension represents the intensities of red pixels, the second plane represents the intensities of green pixels and the third plane reflects the intensities of the blue line. This convention makes

working with MATLAB images identical to working with any other form of matrix data offering the full power of MATLAB for applications in image processing.

\section{Convolutional Neural Network (Cnn):}

CNN used to get some positive results and win well-known competitions. Convolutional layers are added to transform a signal or an image with kernels to get feature maps. So, a unit in a feature map is connected through the weights of the kernels to the previous layer. During the training phase, the weights of the kernels are adapted by back propagation to enhance certain features of the input. Because the kernels are shared between all units of the same function maps, Convolutionary layers have less weights to train than thick FC layers, making CNN easier to train and less prone to over fitting. In addition, since the same kernel is converted over the whole image, the same feature is detected independently of the invariance of the location translation.

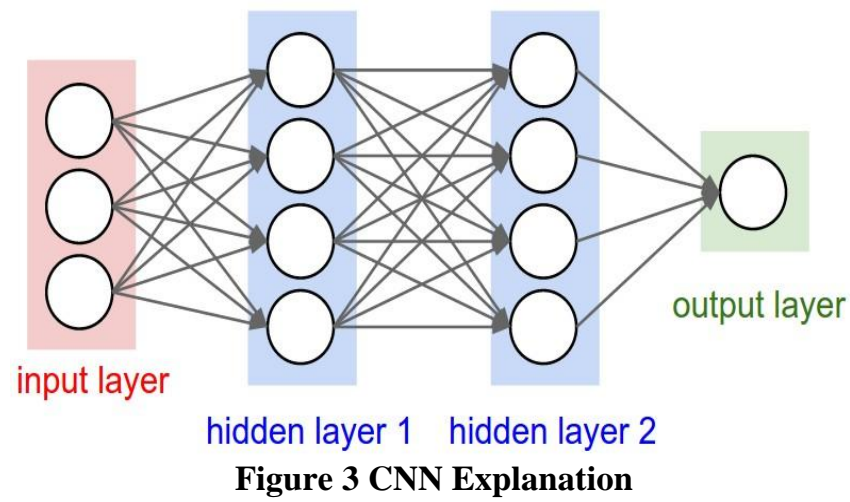

\section{RESULT}

In the experiments, data sets of hand gestures are used to determine the efficiency of the proposed method. The data set is an image collection of 12different gestures. For each gesture, 50 images are captured using the phone camera in different angles. So, there are total 600 images in total for the implementation. The data are divided in to test and training data $30 \%$ of the images are used for the testing ang $70 \%$ are used for training. All the captured images belong to one single person. These gestures are labeled as 0 , $1,23,4,5,6,7,8,9,10,11,12$. After training the data we have got an accuracy rate of 0.9784 , we have showed it in the figure4 below.

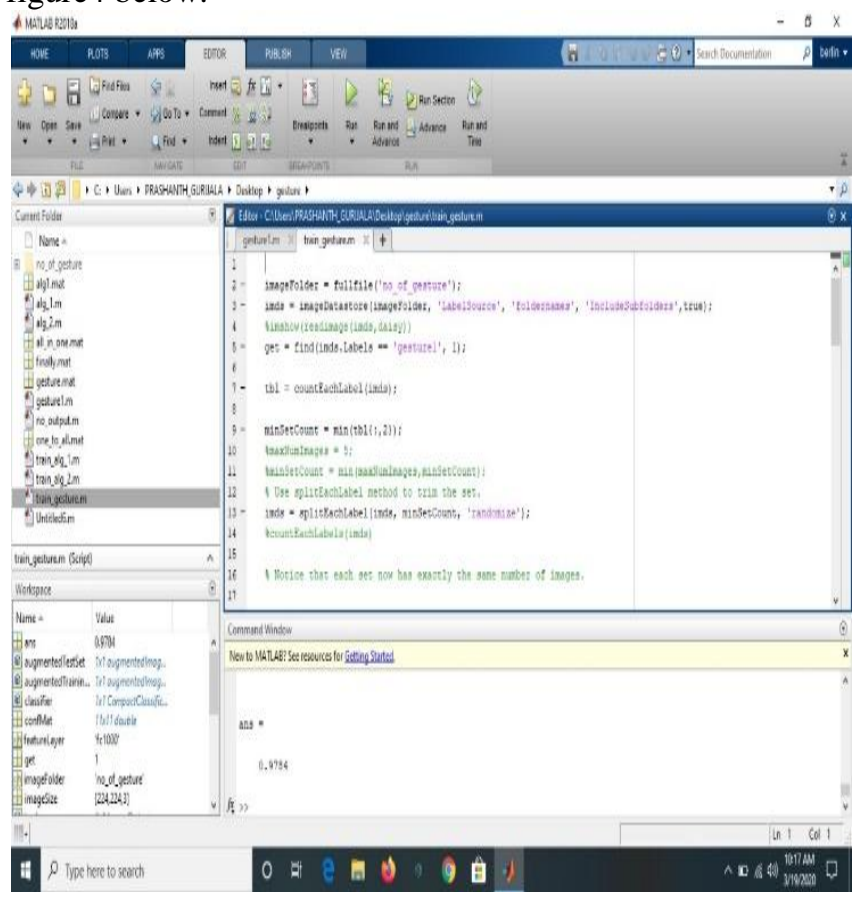

Figure4 Accuracy rate

After training the data set, now we capture the image lively using the IP webcam app, and classification of the image is done as shown in figure5.

Published By:

Blue Eyes Intelligence Engineering \& Sciences Publication

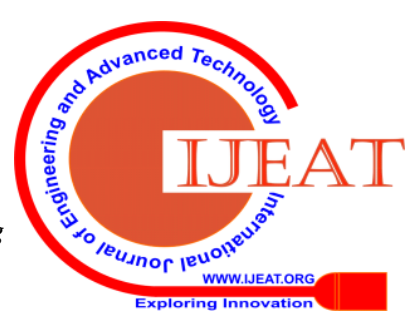




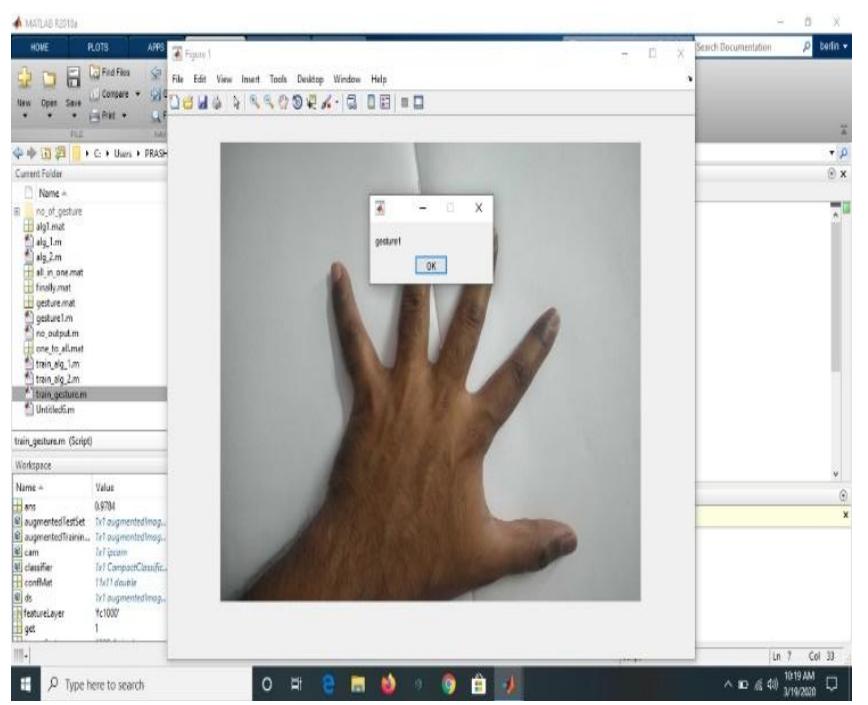

Figure5 Classification of the input given

\section{CONCLUSION}

This paper introduces a solution to basically solve the problems faced by differently abled.

Simple hand gestures are detected and classified using the methodology mentioned. We've seen people drawing with their fingers or creating mini games that would allow you to use the webcam to control the character with gestures but you can use the detection results for whatever you want your application to do.

\section{REFERENCES}

1. Soeb Hussain and RupalSaxena "Hand Gesture Recognition Using Deep Learning”, , ” IEEE SoC Design Conference, 2017.

2. Meenakshi Panwar, "Hand Gesture Recognition based on Shape Parameters" IEEE International Conference on Computing, Communication and Applications (ICCCA), pp. 544-547, 2012.

3. Saransh Sharma and Dr.Samyak Jain "A Static Hand Gesture and Face Recognition System For Blind People" conference, ,IEEE 2011.

4. JayshreeKatkar,OmkarKahane " Hand Gesture Recognition And Device Control" International Journal of Engineering Technology Science and Research(IJERT),Volume 4, April 2017.

5. User friendly smart home infrastructure, Vidyasag Potdar, Dr. cesar Ortega-sanchez , IEEE conference ,IEEE DEST 2011

\section{AUTHOR PROFILE}

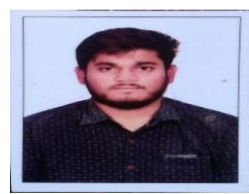

G. Vamsi Krishna Reddy, currently pursuing B.tech final year from SRM institute of science and technology,Chennai,TamilNadu. .

vamsikrishnareddygottu9@gmail.com

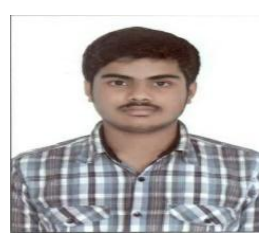

G. Prashanth Kumar, currently pursuing B.tech final from SRM institute of science and technology,Chennai,TamilNadu gurijalaprashanth4@gmail.com

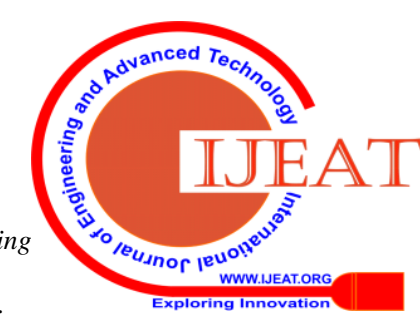

